\title{
Fault Ride Through improvement of Fixed Speed Wind Turbine Using CR-FCL with its Modified Control Strategy
}

\author{
Seyed Behzad Naderi ${ }^{1}$, Michael Negnevitsky ${ }^{1}$, Amin Jalilian ${ }^{2}$, and Mehrdad Tarafdar $\mathrm{Hagh}^{2}$ \\ ${ }^{1}$ School of Engineering and ICT, University of Tasmania, Australia \\ ${ }^{2}$ Faculty of Electrical and Computer Engineering, University of Tabriz, Iran \\ Seyedbehzad.Naderi@utas.edu.au
}

\begin{abstract}
This paper proposes a controllable resistive type fault current limiter (CR-FCL) with its modified control strategy to improve fault ride-through capability (FRT) of fixed speed wind turbine (FSWT). Investigated system includes squirrel cage induction generator, the CR-FCL, and the FSWT connected to infinite bus through double-circuit transmission line. The CRFCL is located in beginning of the parallel line. The proposed structure with its modified control method inserts an optimum value of resistance during fault to achieve maximum FRT capability. It will be shown that this optimum value depends on fault location and pre-fault active power. Two different wind speeds will be applied to the investigated system, which cause two various output powers. Then, it will be proved that each condition needs its own optimum resistance during the fault to achieve the maximum FRT capability of the FSWT. PSCAD/EMTDC is utilised to show accuracy of the proposed scheme and analytical analysis.
\end{abstract}

Index Terms--fault current limiter, fixed speed wind turbine, fault ride through, optimum resistance, fault location, wind speed;

\section{INTRODUCTION}

Increased power demand and the depletion of energy resources have resulted in more attention being paid to renewable energy [1]. Of all renewable energy sources, wind power is the most important, especially in places located in high altitudes or which have more coastlines like Tasmania; because the mean value of the wind speed would be higher than places which are far from coastal areas [2]. With high penetration level of the wind power, there are two significant problems during the fault occurrence. One of the problems is linked to the whole power network: an increasing short-circuit current level. Another problem is related to fault ride-through (FRT) capability of the wind turbine [2-4].

Simply, the wind turbine generators are divided into fixed speed and variable speed [5]. The most interesting one is variable speed wind turbine (VSWT) due to the possibility of extracting more energy from a wind regime than fixed speed wind turbine (FSWT). Furthermore, enhanced power quality, low stress on the turbine and independent control of reactive and active powers are the advantages of the VSWT [6]. A large number of the FSWT has also been installed over the past decades and more will continue to be installed due to their low cost of installation and maintenance, as well as their reliable and robust characteristics $[5,7]$.

In the literature, many methods and structures have been proposed and implemented to improve the FRT capability of the FSWT and decrease the high short-circuit current level during the fault. These methods are different types of the FCLs [8-10], energy storage structures [11], static synchronous compensator (STATCOM) [7], distributed constant power loads (CPLs) [5], dynamic voltage restorer (DVR) [12], series dynamic braking resistor (SDBR) [13], unified power quality conditioner (UPQC) [14], capacitor banks [15], static VAR compensator (SVC) [16] and unified power flow controller (UPFC) [17].

In $[8,9]$, bridge type fault current limiters (BFCLs) have been utilised to enhance the FRT of the FSWT during the fault. A fixed impedance has entered the fault line, which is not appropriate in providing maximum FRT capability of the FSWT. Recently, in [10], three sets of single phase optimum resistive type fault current limiter (OR-FCL) has been proposed. The OR-FCL has good operation for all gird faults. But, number of components is high and each OR-FCL needs its own control circuit.

In this paper, a controllable resistive type fault current limiter (CR-FCL), with a modified control method, will be presented to improve the FRT capability of the FSWT. The CR-FCL aims to obtain the maximum FRT of the FSWT considering all the pre-fault situations. Both the fault location and the wind speed variations will be employed in analytical analysis to produce an optimum technique by the CR-FCL. This technique will ensure the maximum FRT of the FSWT after the fault occurrence. Furthermore, technical issues will be studied; and the possibility of utilising the proposed CR-FCL will be analysed from a practical point of view. The CR-FCL has simple control circuit and low number of components. Finally, simulation results from PSCAD/EMTDC software 
will be obtained to show the effectiveness of the CR-FCL in obtaining the maximum FRT of the FSWT.

\section{FiXed SPEed Wind TURBine}

To simulate the FSWT, it is supposed that the wind turbine has horizontal axis with three blades utilised to extract the power from the wind. The single phase circuit model of the induction generator is shown in Fig. 1. Resistances of the stator and the rotor are shown by $r_{s}$ and $r_{r}^{\prime}$, respectively. In addition, $X_{s}$ and $X_{r}^{\prime}$ refer to the leakage reactance of the stator, and the rotor, respectively. Furthermore, $X_{m}$ is the magnetising reactance and $U$ is the terminal voltage of the squirrel cage induction generator. The stator current which feeds the power system and slip are shown by $I_{1}$ and $s$.

\section{Power Circuit Topology of the Proposed CR-FCL}

Fig. 2 shows three phase power circuit topology of the proposed CR-FCL. Considering Fig. 2, a three phase transformer known as an "isolation transformer" is located in series with the power system. In addition, a three phase diode rectifier bridge is used to insert dc side resistance into the ac side of the proposed CR-FCL. The resistance, $R$, placed in parallel with a self-turnoff switch, plays the main role in limiting the line current during the fault. It is obvious that the line current will increase intensely in the first moments of the fault. So, to protect the self-turnoff switch against the severe line current variation, a small value of dc reactor, $L_{d}$, is placed in series with the switch.

The proposed structure does not affect the normal operation of the power system because $R$ is bypassed by the self-turnoff switch. When a fault occurs, the current of the induction generator increases immediately. When this current reaches pre-specified value, $I_{0}$, the proposed control method is employed to the CR-FCL. Therefore, the self-turnoff switch starts switching with a pre-defined frequency, $f_{s}$, and a duty cycle, $D$. By using this special switching pattern, the proposed CR-FCL is able to insert a controllable value of the resistance to the fault line. So, the fault current is limited to the desired value which makes the maximum FRT of the FSWT. After the fault removals, the CR-FCL returns to the pre-fault condition.

To show the detailed operation of the CR-FCL during the fault, Fig. 3 is used. Considering Fig. 3, the fault occurs at $t_{f}$ and $L_{d}$ starts to charge. At $t_{o f f}$, the dc side current, $i_{d c}$, reaches to $I_{0}$. From $t_{o f f}$, the self-turnoff switch starts the switching. At this interval, average of steady state dc current $\left(I_{s s, a v}\right)$ can be expressed by (1):

$I_{S S, a v .}=\frac{\frac{2 V_{D S}}{R}\left(1-e^{-\frac{R(1-D)}{L_{d}} f_{s}}\right)+\frac{V_{D S}}{L_{d}} \frac{D}{f_{s}}\left(1+e^{-\frac{R(1-D)}{L_{d} f_{s}}}\right)}{2\left(1-e^{-\frac{R(1-D)}{L_{d} f_{s}}}\right)}(1)$

where $V_{D S}$ is the rectified dc side voltage of the CR-FCL.

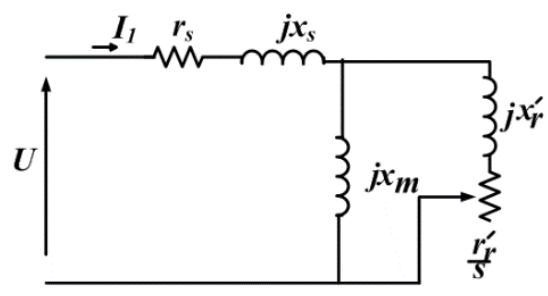

Fig. 1. Single phase equivalent circuit of the squirrel cage induction generator.

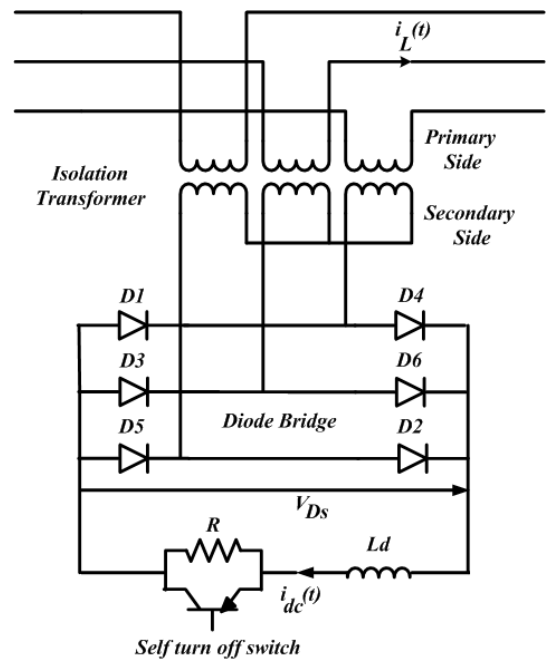

Fig. 2. The three phase power circuit topology of the proposed CR-FCL.

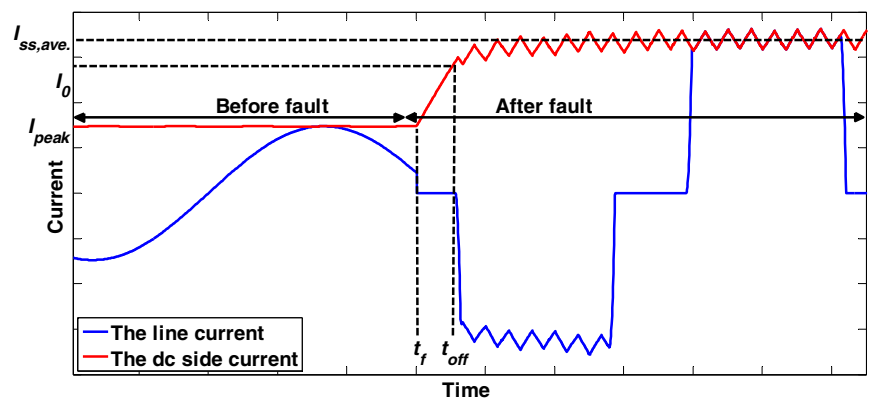

Fig. 3. The line current trend before and after the fault.

By simplifications (assumed that $f_{s}$ has large value.), (1) can be simplified to (2) as follows:

$$
I_{s s, a v .}=\frac{V_{D s}}{R(1-D)}
$$

Equation (2) shows that the value of $I_{s s, a v}$ depends on the $D$. It means that by the controlling $D$, it is possible to control the value of the dc side resistance, $R_{d c}$ as expressed in (3).

$$
R_{d c}=R(1-D)
$$

As a matter of fact, the duty cycle of switching pattern results in the variable and the controllable resistance in the $\mathrm{dc}$ side of the proposed CR-FCL. To make the maximum FRT of FSWT in all pre-fault conditions, this controllable resistance can be applied to the power system. The calculation procedure used to obtain the maximum FRT capability is explained in 
next section in details.

Furthermore, it is important to note that the ac side resistance value of the CR-FCL, $R_{a c}$, is different from the value of $R_{d c}$. To compute the relation between the values of $R_{a c}$ and $R_{d c}$, the active powers in ac, $P_{a c}$, and dc side, $P_{d c}$, of the proposed CR-FCL are considered. If power losses are neglected in both the ac side and the dc side of CR-FCL, the following equation is concluded:

$$
P_{a c}=P_{d c}=3 \frac{\left(V_{m} / \sqrt{2}\right)^{2}}{R_{a c}}=\frac{\left(\frac{6}{\pi} \sin \left(\frac{\pi}{3}\right) a V_{m}\right)^{2}}{R_{d c}}
$$

where $V_{m}$ is the peak voltage value of the primary side of the isolation transformer and $a$ is the isolation transformer ratio. Finally, with regard to (4) we have:

$$
R_{d c}=\left(\frac{18 a^{2}}{\pi^{2}}\right) R_{a c}
$$

\section{MAXIMUM FRT OF FSWT}

During the fault, the CR-FCL is expected to consume the excess energy of the fault. But the amount of the consumed excess active power determines how the FSWT can ride through the fault. To reach the maximum FRT of the FSWT, it is required to create a situation in which the fault does not affect the induction generator. In fact, the output active power of the induction generator should be equal with the pre-fault condition's active power, during the fault.

Overall, the consumed active power of the proposed CRFCL $\left(P_{C R-F C L}\right)$ can be expressed as follows which should be equal with the pre-fault condition's active power of the FSWT, during the fault:

$$
P_{C R-F C L}=\frac{V_{P C C}^{2} R_{a c, o p t}}{R_{a c, o p t}^{2}+k^{2} X_{L}^{2}}=\frac{P_{g}}{2}
$$

where $V_{p c c}$ is the point of common coupling voltage and $k$ is the ratio of the fault distance to the parallel line length. Meanwhile, $P_{g}$ is the output power of the induction generator and $R_{a c, o p t}$ is the optimum resistance value of the CR-FCL to reach the maximum FRT of the FSWT. So, $R_{a c, o p t}$ can be computed as follows:

$$
R_{a c, o p t}=\frac{V_{P C C}^{2}+\sqrt{V_{P C C}^{4}-P_{g}^{2} k^{2} X_{L}^{2}}}{P_{g}}
$$

From (7), it is obvious that $R_{a c, o p t}$ depends on $P_{g}$ and $k$. To show the impact of $P_{g}$ and $k$ on the value of $R_{a c, o p t}$, variations of these parameters should be analysed.

In Fig. 4, the variation of $R_{a c, o p t}$ is plotted in respect of $P_{g}$ for three different fault locations. Considering Fig. 4, it is concluded that, $R_{a c, \text { opt }}$ changes in a wide range with respect to the pre-fault output active power of the induction generator ( 0.2 to $1 p . u$.). In practical conditions, due to the wind speed variation, the active output power variation of the induction generator is obvious in the power network. So, to provide the maximum FRT of the FSWT in all pre-fault situations, using the proposed CR-FCL is essential. Also, Fig. 4 proves that the variation of $k$ does not have any considerable effect on the value of $R_{a c, o p t}$. So the worse condition has been selected for $k$ during the fault in the simulation and $k$ is equal to zero.

According to (7), to calculate $D$ to provide $R_{a c, o p t}$, the prefault active power should be measured. Therefore, considering (5), $R_{d c, o p t}$ can be computed. As a result, by using (3), $D$ is obtained to insert $R_{a c, o p t}$ to the fault line path. So when the fault occurs, the self-turnoff switch starts the switching with the specified $f_{s}$ and the calculated $D$. Consequently, it is guaranteed that the CR-FCL will consume the pre-fault transferred active power of the fault line and the maximum FRT of the FSWT will be obtained in all pre-fault conditions. In Fig. $4, R_{a c, o p t}$ has been calculated for two case studies of the simulation.

\section{TECHNICAL IsSUES}

In the proposed CR-FCL, two important technical issues should be taken into account. The first one is the operation of the self-turnoff switch and the second one is generated heat in the dc side resistance.

The self-turnoff switch has the special $f_{s}$ and $D$ during the fault, which should be able to switch during the high current level. It is clear that the switching interval depends on the fault duration that is in a short time. During this interval, to satisfy the voltage and current rating of the self-turnoff switch, parallel and series connections of the self-turnoff switch can be employed. Up until now, high rating press-packs self-turnoff switches have been introduced for high power applications [18, 19]. Therefore, the CR-FCL can be applicable for the high output active power of the FSWT.

The second technical issue is linked to the dc side resistance of the CR-FCL. To achieve the maximum FRT of the FSWT, the CR-FCL should consume same active power of the prefault condition of the parallel line. As aforementioned, the fault duration is short in most cases. Therefore, the amount of heat generated in the fault duration can be dispatched after the fault removal. The same operation principle of consuming the output active power of the wind farm by resistance has been utilised in King Island, Tasmania, but, this resistance controls the frequency of the power network by consuming the excess output active power of the wind farm. In fact, the wind turbines produce as much power as possible and if the generation exceeds the consumption, the excess output active power is absorbed by the resistance [20]. The authors hope to employ the proposed CR-FCL for both the present application in King Island and obtaining the maximum FRT of the wind turbines in the same place. 


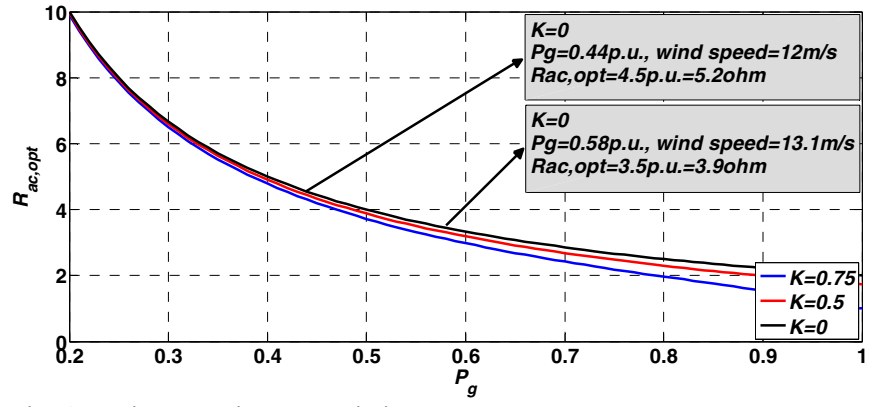

Fig. 4. Optimum resistance variation respect to $P_{g}$.

\section{SimUlation RESUlts}

Simulations by PSCAD/EMTDC software are done on Fig. 5. The parameters of all the components of the simulated power network are presented in Table I. The three phase fault is applied in the beginning of line 1 at $t=15 \mathrm{~s}$ and it continues for $300 \mathrm{~ms}$. When the fault occurs, the current increases. When it reaches $I_{0}=150 \mathrm{~A}$, the CR-FCL operates and limits the fault current level.

Two different cases are studied in this section to show how the resistance value of the CR-FCL can affect the FRT of the FSWT. In both cases, the optimum resistance values are calculated. In addition, it is shown that the resistance value, which is used in one case for the maximum FRT of the FSWT, cannot guarantee the maximum FRT of another case study. Therefore, by employing the proposed scheme, the optimum value of the resistance for each case study will enter to the fault line to ensure the maximum FRT of the FSWT for all case studies.

The difference between the case studies is related to the wind speed value.

\section{A. Case Study 1}

The wind speed is considered $13.1 \mathrm{~m} / \mathrm{s}$. In addition, it is supposed that this speed is constant during the fault. This assumption can be practical because the fault duration is short.

Fig. 6 shows the rotor speed without using the CR-FCL. It is clear that the induction generator is unstable. The induction generator current is presented in Fig. 7. The large swings are clear during and after the fault due to the instability of the induction generator. Fig. 8 illustrates the output active power of the induction generator, as well as the transferred active powers of the fault line (line 1) and the healthy line (line 2).

To limit the fault current and also provide the maximum FRT of the FSWT, the CR-FCL is utilised in line 1. At first, it is necessary to calculate the optimum resistance value of case study 1. The calculation procedure has been discussed in section IV. In Fig. $4, R_{a c, o p t}$ is shown for $V_{\text {wind }}=13.1 \mathrm{~m} / \mathrm{s}$ and $k=0$. To produce $R_{a c, o p t}=3.9 \Omega$ by the CR-FCL in its ac side, the duty cycle should be computed. The value of $51 \%$ for the duty cycle can be concluded using (3) and (5).

Considering Fig. 9, it is completely clear that not only the induction generator remains stable but also the rotor speed has very small swings after the fault removal.

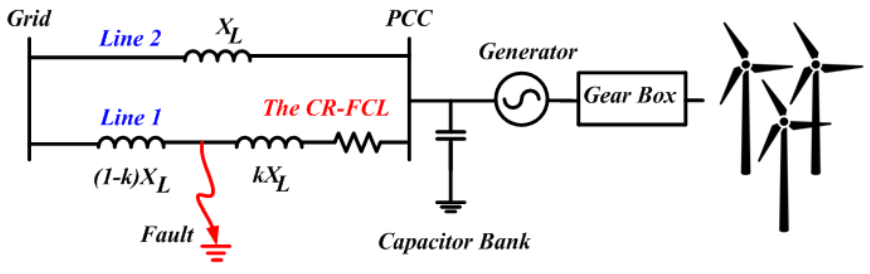

Fig. 5. Single line diagram of the investigated system.

The currents of the induction generator and two parallel lines are also shown in Fig. 10. The induction generator current has a small distortion during the fault due to the CR-FCL operation, Fig. 10(a). However, the most important issue, which should be taken into account, is the current of the healthy line (line 2), Fig. 10(c). By employing the CR-FCL, it can be ensured that the healthy line almost does not sense the fault occurrence.

The transferred powers in both parallel lines are shown in Fig. 11, which prove that the transferred active powers in both parallel lines manifest the pre-fault trend. Finally, the generated impedance by the CR-FCL including the enlarged view of first moments of the fault is shown in Fig. 12. As is clear from Fig. 12, in each switching period, the impedance value of the CR-FCL increases step by step up until it reaches its optimum value.

\begin{tabular}{|c|c|c|}
\hline $\begin{array}{l}\text { Wind } \\
\text { Turbine }\end{array}$ & \multicolumn{2}{|c|}{$\begin{array}{l}\text { TABLE I. SIMULATION PARAMETERS } \\
\text { Rated angular mechanical speed: } 1000 \mathrm{rpm} \text {; } \\
\text { Rotor Radius: } 10 \mathrm{~m} \text {, Air density: } 1.229 \mathrm{~kg} / \mathrm{m}^{\wedge} 3 \\
\text { Wind speed: Case study } 1: 13.1 \mathrm{~m} / \mathrm{s} \\
\text { Case study } 2: 12 \mathrm{~m} / \mathrm{s}\end{array}$} \\
\hline $\begin{array}{l}\text { Squirrel Cage } \\
\text { Induction } \\
\text { Generator }\end{array}$ & \multicolumn{2}{|c|}{$\begin{array}{l}230 \mathrm{~V}, 200 \mathrm{~A} ; 138 \mathrm{kVA} \\
\text { Stator resistance: } 0.066 \mathrm{p} . \mathrm{u} . \\
\text { Rotor resistance: } 0.018 \mathrm{p} . \mathrm{u} . \\
\text { Stattor leakage reactance: } 0.046 \mathrm{p} . u . \\
\text { Magnetising reactance: } 3.86 \mathrm{p} . \mathrm{u} . \\
\text { Rotor reactance: } 0.105 \mathrm{p} . \mathrm{u} . \\
\text { Plolar moment of inertia: } 5 \mathrm{~s} \text {, }\end{array}$} \\
\hline Parallel Lines & \multicolumn{2}{|c|}{ Reactance: 1.36p.u., Capasitor bank: 20kVAR } \\
\hline \multirow[t]{2}{*}{ The CR-FCL } & dc side & $\begin{array}{l}R=15 \Omega, L_{d}=0.01 \mathrm{H} \\
\text { Voltage drop on diodes }=3 \mathrm{~V} \\
\text { Voltage drop on the self turn off } \\
\text { switch }=3 \mathrm{~V} \\
f_{s}=1 \mathrm{kHz}, D=0-100 \%\end{array}$ \\
\hline & $\begin{array}{c}\text { Isolation } \\
\text { Transformer }\end{array}$ & $230 / 230 \mathrm{~V}, 150 \mathrm{kVA}, 0.02 p . u$. \\
\hline
\end{tabular}

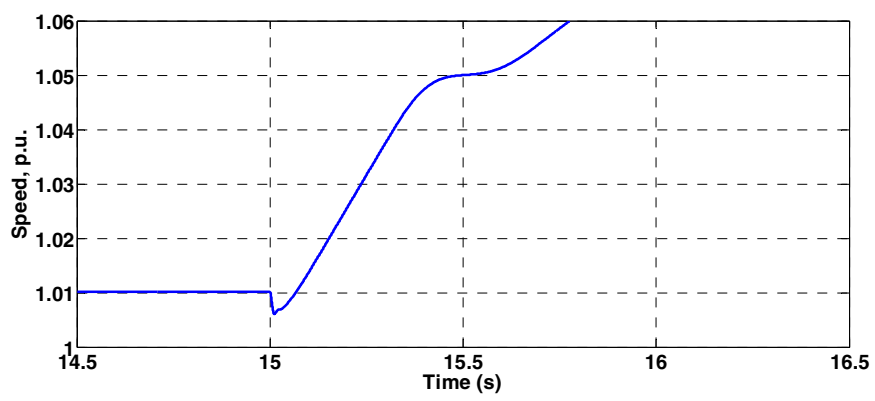

Fig. 6. The rotor speed without using the proposed CR-FCL. 


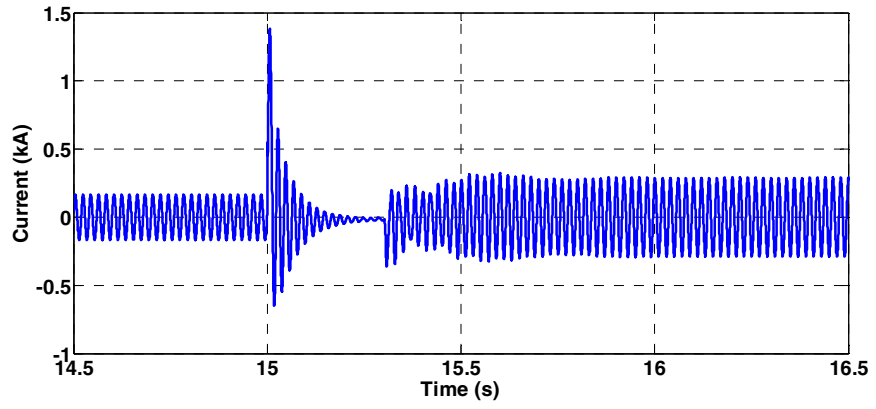

Fig. 7. The induction generator current without using the proposed CR-FCL.

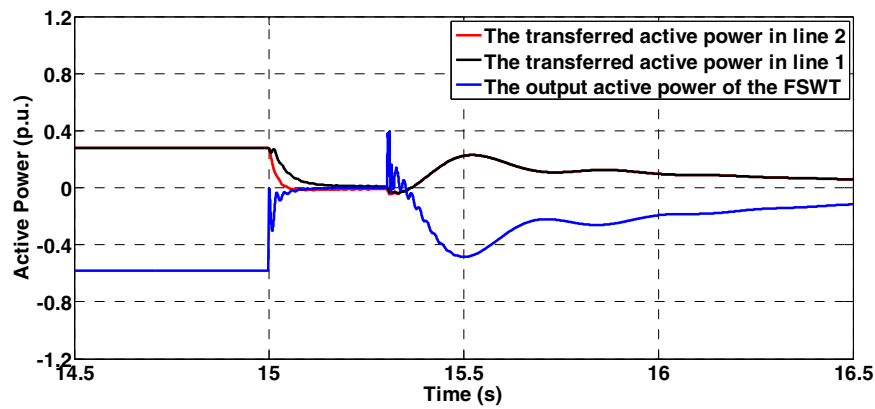

Fig. 8. The transferred and generated active powers during the fault without using the proposed CR-FCL.

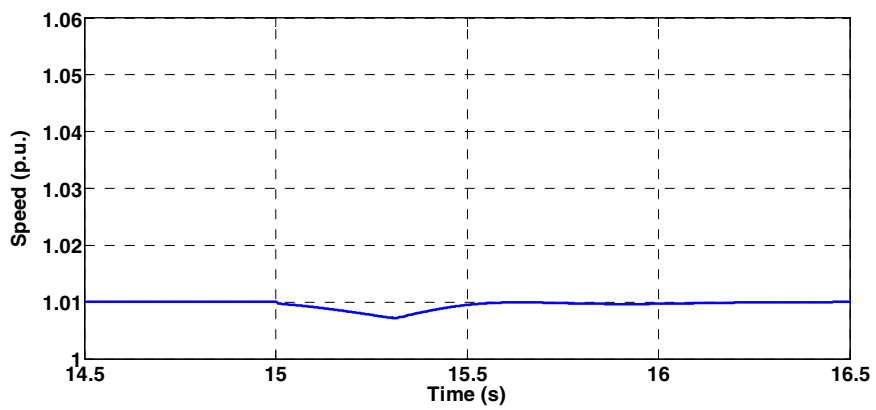

Fig. 9. The rotor speed using the optimum resistance value for case study 1 .

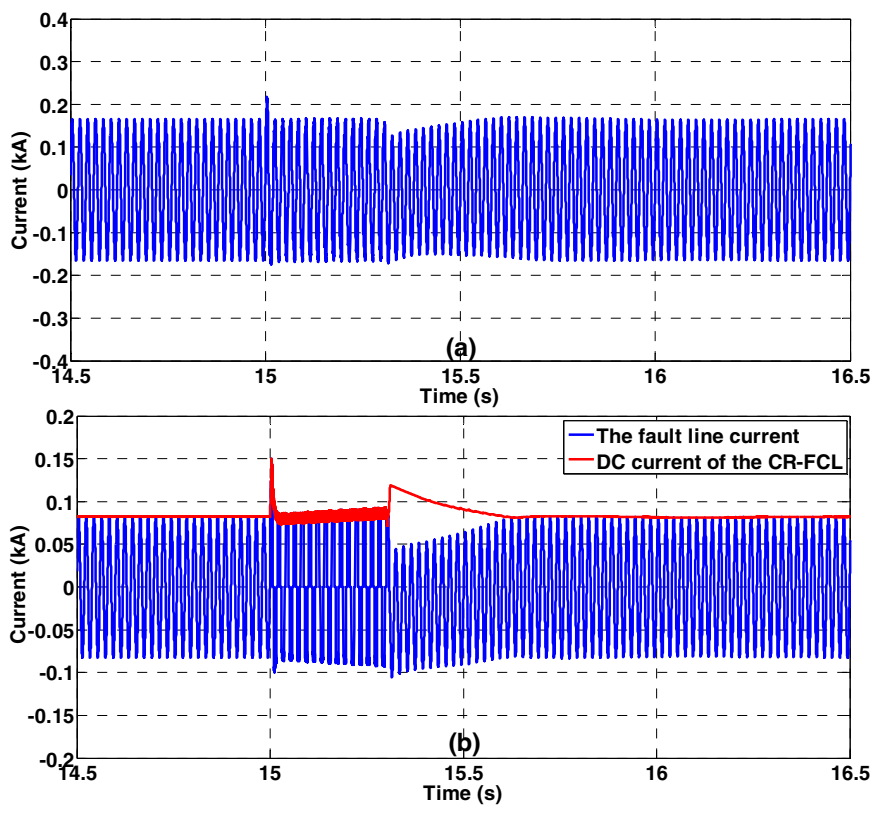

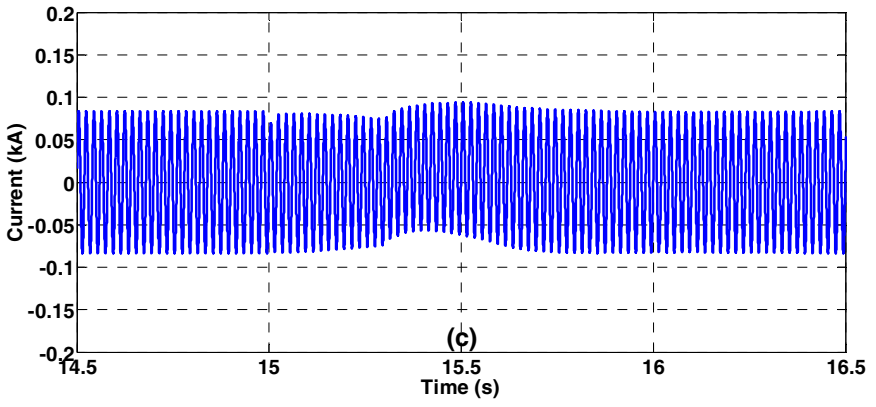

Fig. 10. Inserting the optimum resistance value by the CR-FCL for case study 1 (a) the induction generator current, (b) the fault line current (line 1), (c) the healthy line current (line 2).

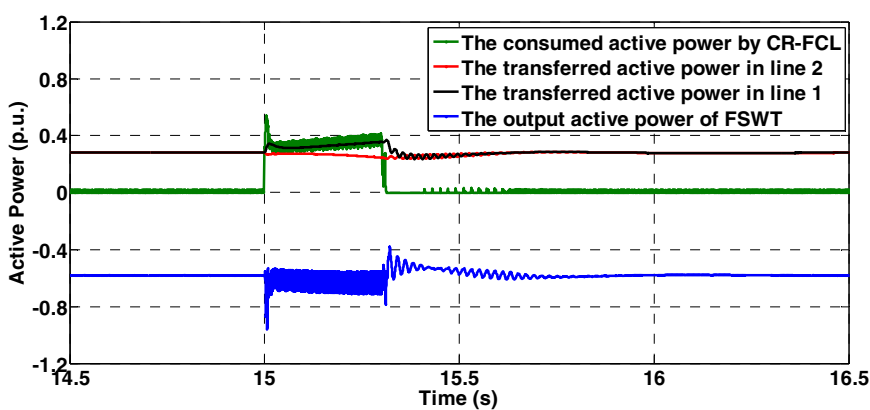

Fig. 11. The consumed active power by the CR-FCL and the transferred and generated active powers for case study 1 .

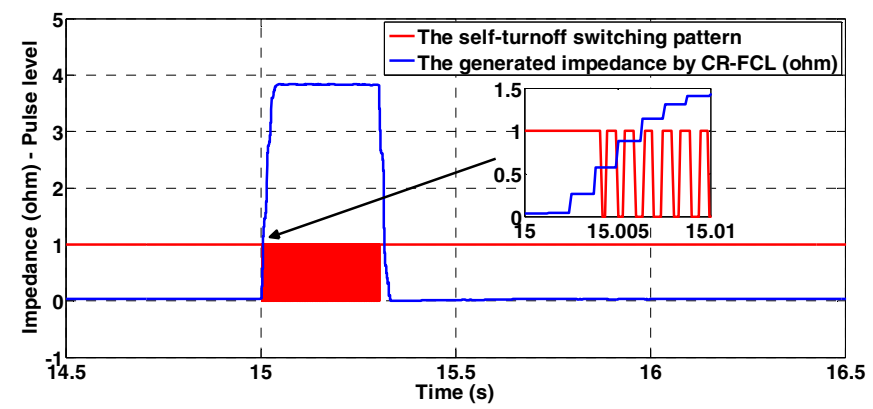

Fig. 12. The produced optimum resistance value by the CR-FCL with $D=51 \%$.

\section{B. Case Study 2}

In this case study, the wind speed changes to $12 \mathrm{~m} / \mathrm{s}$. To obtain the optimum resistance value, the calculation procedure is the same as that mentioned in case study 1 . The optimum resistance value is shown in Fig. 4 . The duty cycle is $36 \%$. To show the benefit of the optimum resistance value, it is assumed that the resistance value of case study $1,3.9 \Omega$, is used for $R_{a c}$ in the CR-FCL. Fig. 13 shows the rotor speed for both values of $R_{a c}=3.9 \Omega$ and $R_{a c, o p t}=5.2 \Omega$. It is clear that the speed swings for $R_{a c, o p t}=5.2 \Omega$ are smaller than $R_{a c}=3.9 \Omega$. To make an effective comparison, the electrical torque of the induction generator is plotted in respect to the rotor speed in Fig. 14. It can be observed that the induction generator is not interested in avoiding the stable equilibrium point for the optimum resistance value. So it can be concluded that inserting the optimum resistance value considering the pre-fault conditions, including the output active power of the FSWT and the fault location, is important from the maximum FRT capability point of view. 


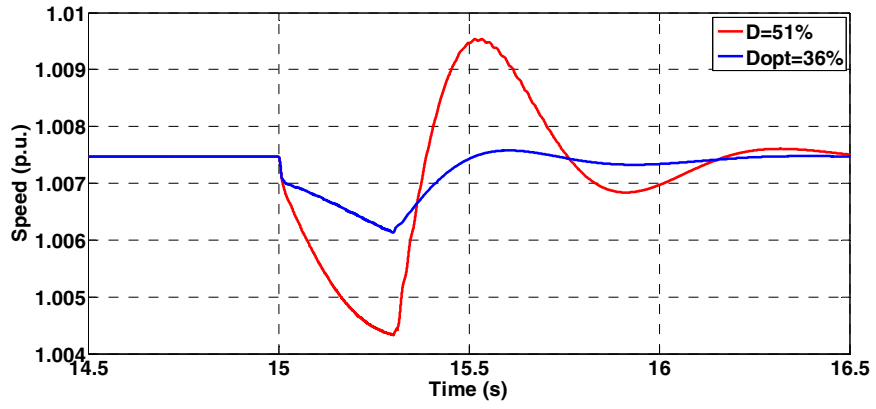

Fig. 13. The rotor speed for two values of the duty cycle.

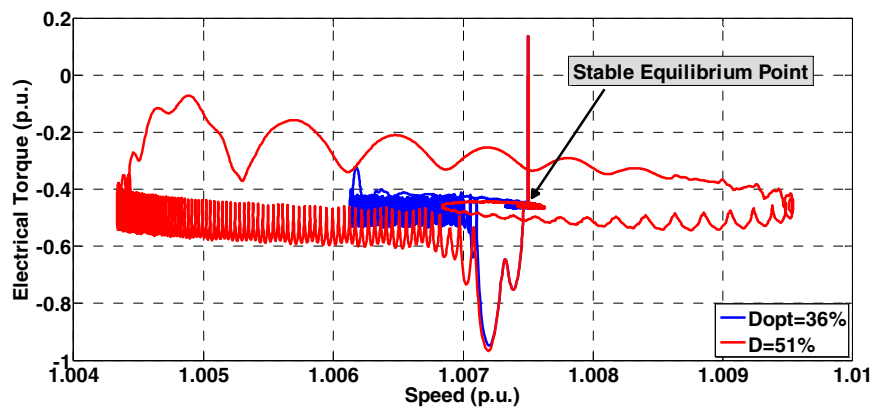

Fig. 14. The electrical torque of the induction generator respect to the rotor speed for two values of the duty cycle by the CR-FCL.

\section{CONCLUSION}

The aim of this paper is to present the complementary study about the FRT capability of the FSWT by the FCLs. In this paper, the FRT capability of the FSWT has been investigated by the modern FCL with its proposed control method. The proposed CR-FCL guarantees the maximum FRT of the FSWT with simple control circuit and low number of components. It has been shown that the FCLs with fixed impedance cannot be effective in reaching the maximum FRT capability for the all pre-fault conditions. The impact of the pre-fault conditions, including the fault location and the pre-fault output active power of the induction generator, has been considered on the maximum FRT of the FSWT. Therefore, the optimum resistance value has been calculated based on the pre-fault conditions. This optimum resistance value can be generated by the special frequency and the duty cycle of the proposed CRFCL. Furthermore, the technical issues, which may arise in practical situations, have been discussed.

\section{REFERENCES}

[1] J.-C. Wu and Y.-H. Wang, "Power conversion interface for smallcapacity wind power generation system," IET Generation, Transmission \& Distribution, vol. 8, pp. 689-696, 2014.

[2] X. Wang, X. Wei, and Y. Meng, "Experiment on Grid-Connection Process of Wind Turbines in Fractional Frequency Wind Power System," Energy Conversion, IEEE Transactions on, vol. PP, pp. $1-10,2014$

[3] S. B. Naderi, M. Jafari, and M. T. Hagh, "Controllable resistive type fault current limiter (CR-FCL) with frequency and pulse dutycycle," International Journal of Electrical Power \& Energy Systems, vol. 61, pp. 11-19, 2014.
$[4]$

[5]

S. B. Naderi, M. Jafari, and M. Tarafdar Hagh, "Parallel-resonancetype fault current limiter," Industrial Electronics, IEEE Transactions on, vol. 60, pp. 2538-2546, 2013.

N. Jelani and M. Molinas, "Asymmetrical Fault Ride Through as Ancillary Service by Constant Power Loads in Grid-Connected Wind Farm," Power Electronics, IEEE Transactions on, vol. 30,

pp. 1704-1713, 2015.
S. Alaraifi, A. Moawwad, M. S. El Moursi, and V. Khadkikar, "Voltage Booster Schemes for Fault Ride-Through Enhancement of Variable Speed Wind Turbines," Sustainable Energy, IEEE Transactions on, vol. 4, pp. 1071-1081, 2013.

C. Wessels, N. Hoffmann, M. Molinas, and F. W. Fuchs, "StatCom control at wind farms with fixed-speed induction generators under asymmetrical grid faults," Industrial Electronics, IEEE Transactions on, vol. 60, pp. 2864-2873, 2013.

[8] M. Firouzi and G. B. Gharehpetian, "Improving Fault RideThrough Capability of Fixed-Speed Wind Turbine by Using Bridge-Type Fault Current Limiter," Energy Conversion, IEEE Transactions on, vol. 28, pp. 361-369, 2013.

[9] G. Rashid and M. H. Ali, "A Modified Bridge-Type Fault Current Limiter for Fault Ride-Through Capacity Enhancement of Fixed Speed Wind Generator," Energy Conversion, IEEE Transactions on, vol. 29, pp. 527-534, 2014.

[10] S. B. Naderi, M. Negnevitsky, A. Jalilian, M. T. Hagh, and K. M. Muttaqi, "Optimum resistive type fault current limiter: An efficient solution to achieve maximum fault ride-through capability of fixed speed wind turbines during symmetrical and asymmetrical grid faults," in Industry Applications Society Annual Meeting, 2015 IEEE, 2015, pp. 1-8.

[11] M. A. Alam, A. H. M. A. Rahim, and M. A. Abido, "Supercapacitor based energy storage system for effective fault ride through of wind generation system," in Industrial Electronics (ISIE), 2010 IEEE International Symposium on, 2010, pp. 2481-2486.

[12] A. A. Hussein and M. H. Ali, "Comparison between DVR and SFCL for fault ride through capability improvement of fixed-speed wind generator," in T\&D Conference and Exposition, 2014 IEEE PES, 2014, pp. 1-5.

[13] A. Causebrook, D. J. Atkinson, and A. G. Jack, "Fault RideThrough of Large Wind Farms Using Series Dynamic Braking Resistors (March 2007)," Power Systems, IEEE Transactions on, vol. 22, pp. 966-975, 2007.

[14] A. Moghadasi and A. Islam, "Enhancing LVRT capability of FSIG wind turbine using current source UPQC based on resistive SFCL," in T\&D Conference and Exposition, 2014 IEEE PES, 2014, pp. 15.

[15] Y. Hu and Z. Chen, "Effects of Capacitor Bank on Fault Ride Through Capability of Induction Generator Based Wind Turbines," in Power and Energy Engineering Conference (APPEEC), 2010 Asia-Pacific, 2010, pp. 1-4.

[16] R. T. Vinakaya, R. M. Shereef, and S. A. Khaparde, "Comparison of SVCs And D-STATCOMs to control voltage violations of fixed speed induction generators," in Power India Conference, 2012 IEEE Fifth, 2012, pp. 1-6.

[17] M. Ferdosian, H. Abdi, and A. Bazaei, "Improved dynamic performance of wind energy conversion system by UPFC," in Industrial Technology (ICIT), 2013 IEEE International Conference on, 2013, pp. 545-550.

[18] B. Abdi, A. H. Ranjbar, G. B. Gharehpetian, and J. Milimonfared, "Reliability Considerations for Parallel Performance of Semiconductor Switches in High-Power Switching Power Supplies," Industrial Electronics, IEEE Transactions on, vol. 56, pp. 2133-2139, 2009.

[19] B. Ju-Won, Y. Dong-Wook, and K. Heung-Geun, "High-voltage switch using series-connected IGBTs with simple auxiliary circuit," Industry Applications, IEEE Transactions on, vol. 37, pp. 1832-1839, 2001.

[20] "King Island, towards a sustainable, renewable energy future," Hydro Tasmania, www.hydro.com.au. 